\title{
Long-Term Effect of Losartan Administration on Blood Pressure, Heart and Structure of Coronary Artery of Young Spontaneously Hypertensive Rats
}

\author{
R. KOPRDOVÁ, M. CEBOVÁ, F. KRISTEK \\ Institute of Normal and Pathological Physiology and Center of Excellence for Cardiovascular \\ Research, Slovak Academy of Sciences, Bratislava, Slovak Republic
}

Received November 29, 2007

Accepted May 5, 2008

On-line July 18, 2008

\begin{abstract}
Summary
Alterations in geometry and structure of coronary arteries have marked consequences on blood flow to the respective area. We evaluated long-term effect of losartan on blood pressure (BP), heart weight/body weight (HW/BW), geometry and structure of septal branch of coronary artery (RS) of young SHR and Wistar rats. Four-week-old Wistar rats and SHR were used. Losartan was administered ( $20 \mathrm{mg} / \mathrm{kg} /$ day) in drinking water by gavage for 5 weeks. BP was measured by plethysmographic method. Cardiovascular system was perfused with a fixative $(120 \mathrm{~mm} \mathrm{Hg})$. RS was processed for electron microscopy. Wall thickness of intima + media (WT), inner diameter (ID), cross-sectional area of intima + media (CSA), volume densities (VD) of endothelial cells $(E C)$, extracellular matrix (ECM) of intima, smooth muscle cells (SMC) and ECM of media were evaluated. BP of 4-week-old SHR did not differ from that of Wistar rats. BP, HW/BW, WT, CSA, WT/ID, CSAs of SMC, ECM of media were increased in 9-weekold SHR, whereas their VD and CSA of EC were decreased. Losartan administration decreased BP and HW/BW in both groups. Geometry of RS was affected only in SHR (reduction of WT, CSA, WT/ID and increased of ID, circumferential tension, VD and CSA of EC). Losartan administration reduced $\mathrm{BP}$ and myocardial mass in both groups and beneficially affected geometry and structure of coronary artery in SHR.
\end{abstract}

\section{Key words}

$\mathrm{SHR} \bullet$ Losartan • Ultrastructure $\bullet$ Coronary artery

\section{Corresponding author}

F. Kristek, Institute of Normal and Pathological Physiology and Center of Excellence for Cardiovascular Research, Slovak Academy of Sciences, Sienkiewiczova 1, 81371 Bratislava, Slovak Republic, Fax: +421 252968516 .

E-mail: frantisek.kristek@savba.sk

\section{Introduction}

There is unequivocal evidence that the pathological background of hypertension and accompanying alterations in function and structure of the cardiovascular system in SHR are of multifactorial origin. Nevertheless, the individual systems do not seem to participate equally. In our previous studies, we observed that neither nitric oxide (NO) deficiency in adult (Kristek et al. 2003) and/or young SHR (Kristek et al. 2007) nor the lack of its substrate L-arginine (Kristek 1998) could be the sufficient cause for development and maintenance of hypertension. Moreover, either long-term phosphodiesterase-5 inhibition with sildenafil (to increase cGMP) from prehypertensive period did not prevent alterations in function, geometry and structure of conduit arteries typical for adult SHR (Kristek et al. 2007). Thus, the different underlying pathophysiological mechanisms seem to be involved in hypertension of SHR.

The studies from other laboratories and also therapeutic effectiveness of either angiotensin converting enzyme inhibitors or angiotensin II (Ang II) receptor blockers suggest an important role of renin-angiotensin system in these processes. Ang II is intimately involved in many regulatory mechanisms in the cardiovascular system beside blood pressure increase. It stimulates proliferation of smooth muscle cells in the arterial wall (Freeman et al. 1995), enhances collagen deposition, influences matrix components (Lopez et al. 2001, Rosendorf 1996), alters structure and thickness of the arterial wall in both resistant and conduit arteries, 
modulates sympathetic activity (Ruiz-Gayo et al. 2000), stimulates endothelin-1 release from vascular endothelium and tunica adventitia (An et al. 2006), influences bioavaibility of $\mathrm{NO}$ and endothelial functions (Yokoyama et al. 2005). Pathological alterations in the majority of these regulatory systems were observed in spontaneous hypertension. Most of the known Ang II effects are mediated via the Ang II type 1 receptor $\left(\mathrm{AT}_{1}\right)$ and therefore administration of angiotensin receptor blocker offers the possibility to modify numerous Ang II actions on the cardiovascular system.

The effect of Ang II itself and the effect of $\mathrm{AT}_{1}$ receptor inhibition are relatively well documented in the resistant part (especially mesenteric bed) of the vasculature. Only very small attention was addressed to the effect of $\mathrm{AT}_{1}$ receptors blockade on the geometry and structure of conduit arteries in SHR. Moreover, data about the effect of $\mathrm{AT}_{1}$ receptor blockade from the prehypertensive period through adulthood on the geometry and structural composition of coronary arteries of SHR have not been studied so far.

The aim of our study was to evaluate whether losartan, an Ang II $\mathrm{AT}_{1}$ receptor antagonist, administered to both normotensive Wistar rats and SHR influences i) blood pressure, ii) heart weight/body weight ratio, iii) geometry of coronary artery, and iv) volume densities and cross-sectional areas of respective parts of the coronary artery wall. Having in mind the fact that pathological changes evoked by hypertension are more difficult to be influenced when they become stabilized we administered losartan from the early prehypertensive period of ontogenic development until early adulthood.

\section{Material and Methods}

All procedures and experimental protocols were approved by the Ethical Committee for Experimental Work of the Institute of Normal and Pathological Physiology, Slovak Academy of Sciences, and conform to the European Convention on Animal Protection and Guidelines on Research Animal Use.

The animals were housed at a temperature of $22-24{ }^{\circ} \mathrm{C}$, under a $12 \mathrm{~h}$ light: dark cycle and fed a regular pellet diet.

Four-week-old Wistar rats and SHR were taken for the study. The animals were divided into four groups of 10 animals each: 1) Wistar rats, 2) SHR, 3) Wistar rats treated by losartan, 4) SHR treated by losartan. Losartan was administered daily by gavage in a dose $20 \mathrm{mg} / \mathrm{kg} /$ day (dissolved in drinking water). The experiment lasted five weeks and in all groups blood pressure (BP) was measured indirectly by the plethysmographic method on the tail artery of prewarmed animals.

At the end of the experiment 9-week-old animals were sacrificed by an overdose of anesthesia, the chest was opened and the cardiovascular system was perfused at a constant pressure of $120 \mathrm{~mm} \mathrm{Hg}$ for $10 \mathrm{~min}$ via a cannula placed in the left ventricle. As a fixative $300 \mathrm{mM}$ glutaraldehyde in $100 \mathrm{mM}$ phosphate buffer was used. After perfusion the hearts were excised and weighed. The proximal part of the septal branch of the left descending coronary artery (RS) was excised, cleaned, divided into three segments (about $1 \mathrm{~mm}$ ), fixed with the same fixative, postfixed with $40 \mathrm{mM} \mathrm{OsO}$, stained en block with uranylacetate, dehydrated through ascending concentration of alcohol and embedded in Durcupan ACM (Sigma). Two randomly selected blocks of the artery were cut perpendicularly to the longitudinal axis. The inner diameter (ID) and arterial wall thickness - tunica intima and tunica media (WT) were measured in light microscopy. The arterial wall thickness was measured at about $45^{\circ}$ intervals around the circumference of the artery. The cross-sectional area of tunica intima and tunica media (CSA) and circumferential tension (BP x ID/WT) were calculated.

In the coronary artery volume densities (VD) of endothelial cells, subendothelial matrix (space between endothelial cells and first layer of smooth muscle cells, including elastic lamina), smooth muscle cells, and extracellular matrix among smooth muscle cells were measured by the point counting method (Weibel et al. 1966) using ultrathin sections. The same blocks used for light microscopic measurements were also used for morphometric measurements at electron microscope level. Volume density was calculated: total number of points falling on a particular structure/total number of points falling on the entire vessel wall (tunica intima + tunica media), expressed as $\mu \mathrm{m}^{3} / \mu \mathrm{m}^{3}$ vessel wall (tunica intima + tunica media). From the values of volume densities, appropriate CSAs were calculated.

Values are given as mean \pm S.E.M. ANOVA and Bonferroni test for unpaired variables were used for statistical evaluation. Results were considered significantly different when $\mathrm{P}<0.05$.

\section{Results}

At the 4th (the beginning of the experiment) and 5 th week of the postnatal life the BP of untreated SHR 


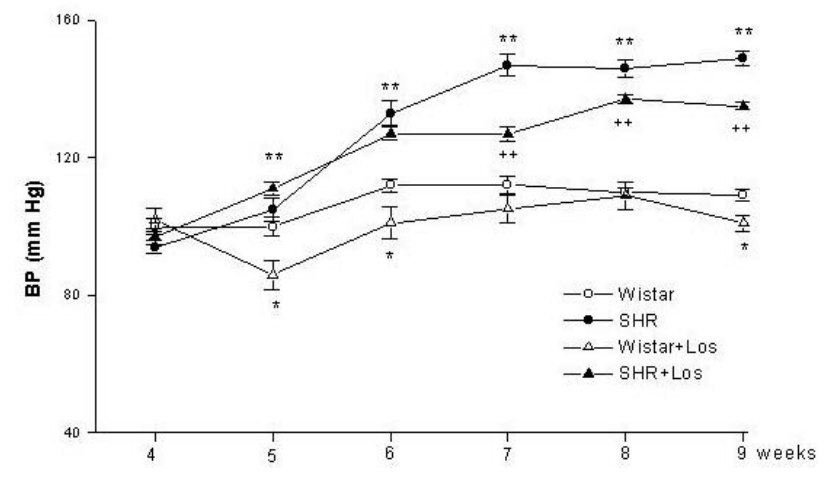

Fig. 1. Blood pressure value (BP) in the course of the experiment. Wistar rats (Wistar), Wistar rats administered losartan (Wistar+Los), spontaneously hypertensive rats (SHR), and SHR administered losartan (SHR+Los). $* \mathrm{p}<0.05, * * \mathrm{p}<0.01$ vs. control Wistar rats, $++p<0.01$ vs. SHR.

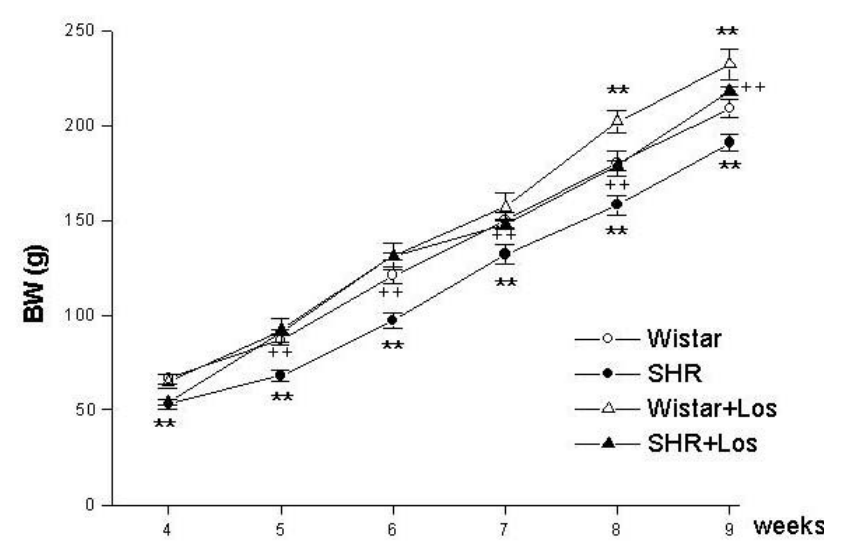

Fig. 2. Body weight (BW) value during the course of the experiment. Wistar rats (Wistar), Wistar rats administered losartan (Wistar+Los), spontaneously hypertensive rats (SHR), and SHR administered losartan (SHR+Los). ${ }^{* *} p<0.01$ vs. Wistar, $++p<0.01$ SHR vs. SHR+Los.

did not differ from the BP of untreated control Wistar rats. In the SHR group BP continually increased from the 5th week of age. In 9-week-old SHR it was increased by $37 \%$. Administration of losartan to Wistar rats evoked BP decrease in the 9th week of age by $7 \%$. BP in SHR after losartan treatment was significantly reduced from the 7th week and in 9-week-old SHR, it was in comparison to untreated SHR decreased by about $10 \%$; but it was still higher (24\%) than in control Wistar rats. (Fig. 1).

Body weight of the control Wistar rats was higher during the entire experiment in comparison to SHR, but the differences were decreasing with age and in the 9 th week it was only $8 \%$. The administration of losartan to Wistar rats evoked an increase of body weight by $11 \%$ in the 9 th week. The body weight was increased in losartan-treated SHR already after the first week of

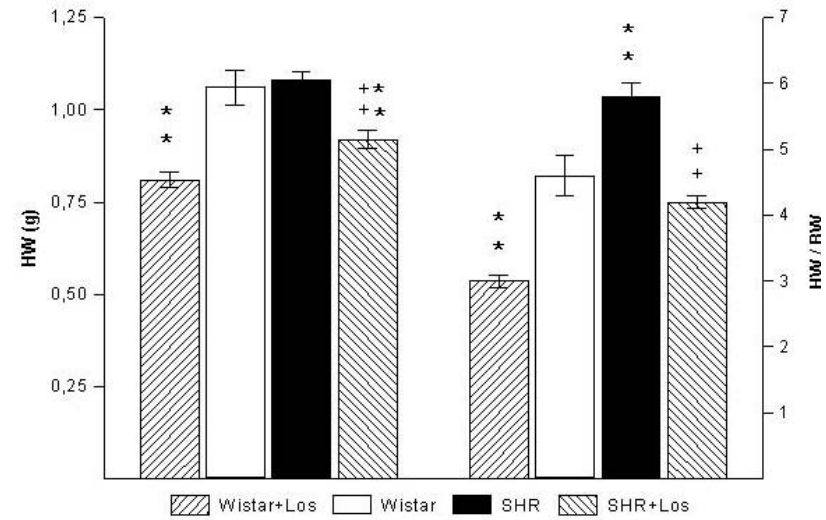

Fig. 3. Heart weight and heart weight/body weight ratio of Wistar rats (Wistar), Wistar rats administered losartan (Wistar+Los), spontaneously hypertensive rats (SHR), and SHR administered losartan (SHR+Los). $* * \mathrm{p}<0.01$ vs. control Wistar rats, $++p<0.01$ vs. SHR.

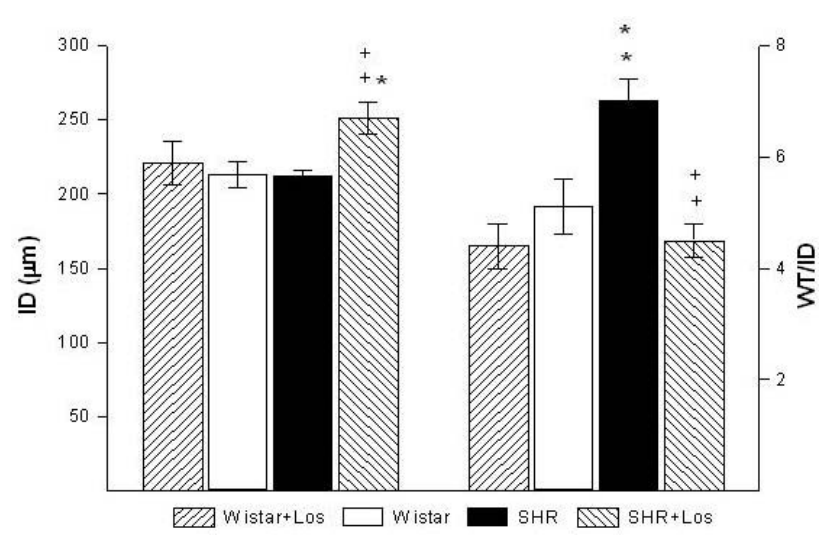

Fig. 4. Inner diameter (ID) and wall thickness/inner diameter ratio (WT/ID) of Wistar rats (Wistar), Wistar rats administered losartan (Wistar+Los), spontaneously hypertensive rats (SHR), and SHR administered losartan (SHR+Los). * p<0.05, ** $\mathrm{p}<0.01$ vs. control Wistar rats, $++p<0.01$ vs. SHR.

treatment (in the 9th week by $14 \%$ ) and it did not differ from the body weight of control Wistar rats (Fig. 2).

Heart weight (heart weight after perfusion with fixative is higher than heart weight without perfusion due to fixative in the open arterial tree) of SHR did not differ from control Wistar rats. Administration of losartan evoked a decrease of heart weight in both Wistar rats $(24 \%)$ and SHR (15\%). Decrease in heart weight was observed between control Wistar rats and SHR receiving losartan (Fig. 3).

Heart weight/body weight $(\mathrm{HW} / \mathrm{BW})$ ratio in SHR was increased (26\%) compared to Wistar rats. Losartan administration resulted in a decrease of HW/BW ratio in both groups, in Wistar rats by $35 \%$, in SHR by $28 \%$. No differences in relative heart weight were found between Wistar rats and SHR receiving losartan (Fig. 3). 


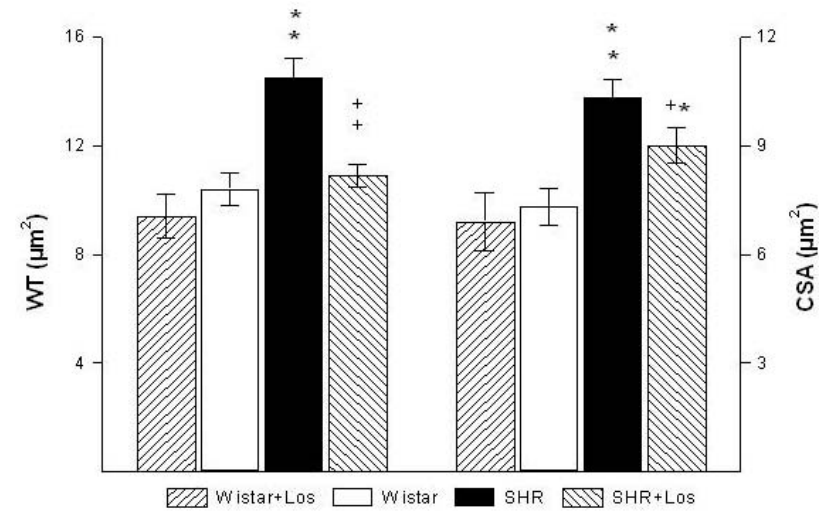

Fig. 5. Wall thickness (WT) and cross-sectional area (CSA) of Wistar rats (Wistar), Wistar rats administered losartan (Wistar+Los), spontaneously hypertensive rats (SHR), and SHR administered losartan (SHR+Los). * $\mathrm{p}<0.05, * * \mathrm{p}<0.01$ vs. control Wistar rats, $+p<0.05,++p<0.01$ vs. SHR.

\section{Geometry of the coronary artery}

The inner diameter of this artery in SHR did not differ from that in Wistar rats. No difference was also found between Wistar rats and Wistar rats treated with losartan. Compared to untreated SHR, losartan administration to SHR resulted in an increase of inner diameter $(18 \%)$, the difference was also significant in comparison with Wistar rats (Fig. 4).

Wall thickness of the artery was increased in SHR (39 \%) when compared with Wistar rats. Administration of losartan to Wistar rats did not evoke any changes in the wall thickness. On the other hand, significant decrease of wall thickness was found in SHR after losartan treatment $(25 \%)$ and this decrease was up to the control level (Fig. 5).

The cross-sectional area (arterial wall mass) of the arterial wall (tunica intima + tunica media) of SHR in comparison with Wistar rats increased by $41 \%$. No difference in this respect was observed between Wistar rats and Wistar rats receiving losartan, but a significant decrease was found in SHR administered losartan (13\%). Nevertheless, arterial wall mass in treated SHR was still higher (19\%) than that in control Wistar rats (Fig. 5).

The value of wall thickness/inner diameter ratio in SHR group was increased by $37 \%$ when compared to control Wistar rats. Long-term administration of the losartan to Wistar rats did not evoke significant effect. Losartan administered to SHR caused a decrease of the ratio by $36 \%$ and at the end of the experiment the wall thickness/inner diameter ratio did not differ from that of the controls (Fig. 4).

Circumferential stress in the coronary artery of the SHR did not differ from that in Wistar rats.

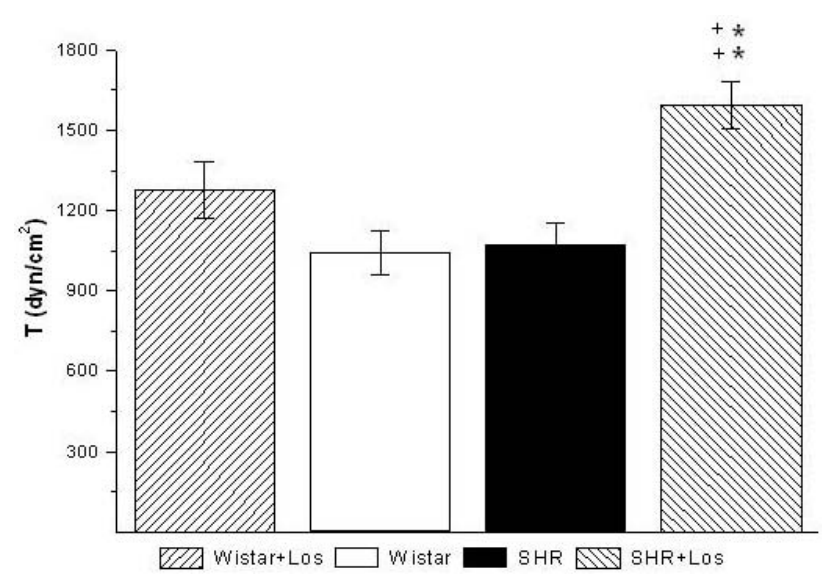

Fig. 6. Circumferential tension $(T)$ in the coronary artery. Wistar rats (Wistar), Wistar rats administered losartan (Wistar+Los), spontaneously hypertensive rats (SHR), and SHR administered losartan (SHR+Los). ** $\mathrm{p}<0.01$ vs. control Wistar rats, $++p<0.01$ vs. SHR.

Administration of losartan to Wistar rats did not cause any effect. Losartan administration to SHR significantly increased circumferential stress in the artery in comparison with both untreated SHR (49\%) and Wistar rats $(53 \%)$ (Fig. 6).

\section{Tunica intima}

In the coronary artery of SHR we observed a decrease of volume density and related CSA of tunica intima. Evaluation of cellular and extracellular parts of the tunica intima showed that there were no differences in the extracellular matrix between SHR and Wistar rats in either VD or CSA. The difference between tunica intima of SHR and Wistar rats was due to decreased VD and CSA of endothelial cells compared with Wistar rats (Tables 1 and 2).

Five weeks of losartan administration to Wistar rats did not evoke changes in either VD or related CSA in tunica intima. No effect of losartan was observed in VD and CSA of endothelial cells and extracellular matrix. On the other hand, the administration of losartan to SHR evoked pronounced effect on the intima. VD and CSA of tunica intima were significantly increased and at the end of the experiment they did not differ from those of normotensive Wistar rats. The analysis of the intima revealed that the VD and related CSA of endothelial cells were significantly increased, whereas both VD and CSA of extracellular matrix were not affected by losartan administration (Tables 1 and 2).

\section{Tunica media}

The tunica media occupied significantly higher 
Table 1. Volume densities of individual parts of arterial wall of Wistar rats, Wistar rats administered losartan (Wistar+Los), SHR, and SHR administered losartan (SHR+Los).

\begin{tabular}{lllll}
\hline Volume density (\%) & Wistar & Wistar+Los & SHR & SHR+Los \\
\hline Tunica intima & $11.49 \pm 1.64$ & $10.85 \pm 2.85$ & $5.40 \pm 0.97^{* *}$ & $9.09 \pm 0.99^{+}$ \\
Endothelial cells & $7.44 \pm 1.16$ & $5.85 \pm 0.95$ & $2.64 \pm 0.61^{* *}$ & $6.66 \pm 0.84^{++}$ \\
Extracellular matrix & $4.04 \pm 0.52$ & $3.52 \pm 1.12$ & $2.74 \pm 0.49$ & $2.41 \pm 0.24^{* *}$ \\
Tunica media & $88.51 \pm 1.64$ & $90.92 \pm 2.08$ & $94.64 \pm 0.97^{* *}$ & $90.97 \pm 1.01^{+}$ \\
Smooth muscle cells & $73.30 \pm 1.94$ & $73.75 \pm 2.30$ & $76.93 \pm 1.28$ & $74.20 \pm 1.23$ \\
Extracellular matrix & $15.21 \pm 1.59$ & $17.13 \pm 1.19$ & $17.71 \pm 0.78$ & $16.71 \pm 1.33$ \\
\hline
\end{tabular}

Values are means \pm S.E.M. $* * p<0.01$ vs Wistar rats, $+p<0.05,++p<0.01$ vs SHR.

Table 2. Cross sectional areas of individual parts of arterial wall of Wistar rats, Wistar rats administered losartan (Wistar+Los), SHR, and SHR administered losartan (SHR+Los).

\begin{tabular}{lllll}
\hline Cross sectional areas $\left(\boldsymbol{\mu \mathbf { m } ^ { 2 } )}\right.$ & Wistar & Wistar+Los & SHR & SHR+Los \\
\hline Total & $7300 \pm 500$ & $6900 \pm 800$ & $10300 \pm 500^{* *}$ & $9000 \pm 500^{*+}$ \\
Tunica intima & $863 \pm 130$ & $629 \pm 162$ & $546 \pm 83^{*}$ & $825 \pm 91^{+}$ \\
Endothelial cells & $557 \pm 86$ & $395 \pm 91$ & $266 \pm 55^{* *}$ & $597 \pm 69^{++}$ \\
Extracellular matrix & $304 \pm 49$ & $235 \pm 76$ & $280 \pm 45$ & $227 \pm 31$ \\
Tunica media & $6883 \pm 994$ & $6156 \pm 1090$ & $10346 \pm 1191^{*}$ & $8420 \pm 625$ \\
Smooth muscle cells & $5665 \pm 765$ & $5036 \pm 971$ & $8446 \pm 1042^{*}$ & $6860 \pm 501$ \\
Extracellular matrix & $1219 \pm 279$ & $1118 \pm 145$ & $1899 \pm 164 *$ & $1600 \pm 177$ \\
\hline
\end{tabular}

Values are means \pm S.E.M.* $p<0.05, * * p<0.01$ vs Wistar rats, $+p<0.05,++p<0.01$ vs SHR.

volume density and CSA in SHR than in normotensive Wistar rats. Analysis of the media showed that CSA of both SMC and extracellular matrix was increased in SHR (Tables 1 and 2).

Administration of losartan to Wistar rats did not evoke changes in both VD and related CSAs in the tunica media and no effect of losartan was observed in volume density and CSA of smooth muscle cells and extracellular matrix (Tables 1 and 2). Opposite to Wistar rats losartan administration to SHR decreased VD and CSA of media and at the end of the experiment both did not differ from those in normotensive Wistar rats (Tables 1 and 2).

\section{Discussion}

Blood pressure increase and cardiac hypertrophy found in 9-week-old SHR as well as the process of BP rise from the prehypertensive period observed in the present study represent the developing phase of hypertension. The findings are fully in agreement with reports from other laboratories (Lee et al. 1983, Cunha et al. 1997) including the original data presented by Okamoto and Aoki (1963).

Five weeks of losartan therapy resulted in a significant decrease of BP and heart weight/body weight ratio in both normotensive Wistar rats and SHR. The preventive effect of losartan against blood pressure elevation in SHR could be connected with i) inhibition of postjunctional Ang II effects via receptors and/or via increased plasma Ang II level with subsequent stimulation of $\mathrm{AT}_{2}$ receptors (Gohlke et al. 1998), ii) affection of a variety of vasoconstrictor mechanisms including endothelin-1 release (An et al. 2006) and adrenergic vasoconstriction (Paulis et al. 2007), and iii) reduction of superoxide anions production (Dantas et al. 2004). All these mechanisms result in prevalence of vasodilatory mechanisms. Ang II was also shown to be one of the most potent mitogens and its reduced action due to $\mathrm{AT}_{1}$ receptors inhibition is probably responsible for the decrease of myocardium mass. It is noteworthy that a lower dose of losartan $(15 \mathrm{mg} / \mathrm{kg})$ administered to 3-week-old SHR for 4 weeks did not influence either 
vascular or cardiac hypertrophy in spite of blood pressure decrease. The regression of vascular and cardiac hypertrophy was observed when treatment was extended to 10 weeks (Morton et al. 1992). The hypotensive effect of losartan and the decrease of heart weight after losartan administration in both normotensive and SHR are in good agreement with the earlier observations (Ruiz-Gayo et al. 2000, Soltis 1993, Soltis et al. 1993, Suo et al. 2002, Li et al. 1997, Silva-Antonialli et al. 2000). Compared with our study a more pronounced decrease of BP (up to control level) after losartan administration was also observed by Soltis et al. (1993) and Kaneko et al. (1996). Higher effect of losartan in those experiments was achieved probably due to application of losartan (the same dose as in our experiment) by subcutaneous injection (Soltis et al. 1993) and/or due to administration of higher doses of losartan $-30 \mathrm{mg} / \mathrm{kg} /$ day (Kaneko et al. 1996).

At the end of the experiment heart weight/body weight ratio in treated SHR was even beneath the value of untreated Wistar rats. BP in treated SHR was significantly lower than in untreated SHR, but it was still significantly higher in comparison to Wistar rats. Thus, our results imply higher antiproliferative (about $-30 \%$ ) as antihypertensive (about $-8 \%$ ) effect of losartan in SHR. The question arose whether a higher effect of losartan on heart weight/body weight ratio compared with BP in both groups is a real beneficial effect of losartan, since relatively decreased mass of myocardium has to surmount relatively higher resistance compared to untreated rats. Moreover, the finding also indicates that these two parameters are not necessarily coupled. Similar results were observed after NO donors and/or sildenafil administration to young and/or adult SHR (Kristek et al. 2003, Cebová et al. 2006, Kristek et al. 2007).

In SHR we observed alterations in the geometry of the coronary artery signalizing hypertrophy of the arterial wall - increased wall thickness, cross-sectional area, and wall thickness/inner diameter ratio. No difference was found in inner diameter. Hypertrophy of the arterial wall at this age was documented by many authors in various arteries (Owens and Schwartz 1982, Cunha et al. 1997, Rizzoni et al. 1998). Nevertheless, Lee et al. (1983) observed hypertrophy of the arterial wall in the first order branch and small arterioles of the superior mesenteric artery (SMA) in 10- to 12-week-old SHR but not in SMA itself.

In spite of pronounced alterations in the geometry of coronary artery in SHR the circumferential stress (BP $\mathrm{x}$ radius/wall thickness) did not differ from that in Wistar rats. It means that BP increase in SHR was properly balanced by increased WT/ID ratio. No differences in circumferential stress of the carotid artery between 12-week-old SHR and age-matched Wistar rats was also reported by Cunha et al. (1997).

Losartan administration evoked a higher effect on the geometry of the coronary artery in SHR compared to Wistar rats. We suggest that augmented vasodilating effect (ID in SHR was increased at about $18 \%$, contrary to about $3 \%$ in Wistar rats) and higher antiproliferative effect (WT and CSA were reduced at about $25 \%$ and $13 \%$ in SHR, vs. about $10 \%$ and $5 \%$ in Wistar rat) rather than antihypertensive effect in SHR after losartan administration disturbed the balance among the parameters participating on circumferential stress and due to this WT/ID ratio was too low for a given intraluminal pressure. This resulted in significant increase of circumferential stress. Increased circumferential stress appears to be one of the most important stimuli leading to hypertrophy of the arterial wall. Having in mind the findings of Thubrikar and Robicsek (1995) that decrease of circumferential stress inhibits atherogenesis, we suppose that the opposite could aggravate the pathological processes in the arterial wall. Since the effect of losartan on the geometry of the coronary artery seems to be greater than that expected on the basis of BP reduction, our data suggest that losartan may also induce structural changes in the heart and blood vessels by a pressure-independent mechanism.

Evaluation of volume densities of the coronary artery wall components and calculation of related CSAs revealed some differences between SHR and Wistar rats. In spite of hypertrophy of the arterial wall in SHR CSA of their intima did not reach the value seen in normotensive Wistar rats. More detailed analysis of the intima in SHR revealed that only volume density and CSA of endothelial cells were significantly reduced compared with Wistar rats. The findings support a suggestion that hypertension in SHR may depend, at least partially, on the compromised function of endothelial cells (Pourageaud and Freslon 1995, Liu et al. 2002). This agrees well with our previous findings documenting the decreased endothelium-dependent relaxation to acetylcholine in the iliac artery from SHR (Gerová et al. 2005). However, in a parallel series of experiments we observed that long-term increase of either NO level or cGMP (from prehypertensive period until the 9th week) had no effect on the BP, heart/body weight ratio, and 
geometry of the coronary and carotid arteries in SHR (Kristek et al. 2007). We hypothesized that other regulatory mechanisms than nitric oxide should be involved.

The tunica media represents about $95 \%$ of the arterial wall in SHR and it is responsible for the increase of the arterial wall mass. The analysis of the tunica media revealed that both parts - smooth muscle cells and extracellular matrix - participate in the hypertrophy of the arterial wall equally. Since we did not observe mitotic activity of smooth muscle cells in the coronary artery wall of SHR, it is likely that the increase of wall thickness was due to hypertrophy of these cells rather than due to their hyperplasia. The finding is in accordance with the suggestion that in slowly developing models of hypertension (including SHR) the major growth response in large arteries was mainly due to hypertrophy of smooth muscle cells (Olivetti et al. 1980, 1982).

To our knowledge there are no literary data to compare volume densities and CSAs of individual components of the coronary artery wall in 9-week-old Wistar rats and age-matched SHR. Increased tunica media and decreased mass of endothelial cells support experimental studies suggesting that the presence of a functional endothelium is essential for maintaining smooth muscle cells in a non-proliferative state (Garg and Hassid 1989). Increased CSA of smooth muscle cells is in accordance with greater active tension of SHR arteries compared with vessels from Wistar rats (Mulvany et al. 1980, Ruiz-Gayo et al. 2000). Lee et al. (1983) observed significant differences in volume densities and CSAs of majority of components in large mesenteric arteries and to a less extent also in small vessels of 10-week-old SHR when compared with Wistar-Kyoto rats. On the other hand, they did not find differences in volume densities and CSAs of any components in media of the superior mesenteric arteries. Inconsistent results among individual arteries suggest different answers of various parts of the arterial tree to the similar stimulus so that it is impossible to transform results from one vessel to another.

Five weeks of losartan administration to Wistar rats did not result in any effect on volume densities and corresponding CSAs of individual components of arterial wall. On the other hand, losartan administration to SHR evoked pronounced effect on the arterial wall but these effects were different on intima than on media. The analysis of the intima revealed increased mass of endothelial cells in the arterial wall. We suggest that it could be responsible for improvement of physiological regulatory mechanisms as it was observed in vessels after losartan treatment. We found enhanced endotheliumdependent relaxation to acetylcholine in the thoracic aorta after losartan administration (Török et al. 2006). Improved acetylcholine-induced relaxation was also observed by Soltis (1993) in SHR aorta after two weeks of losartan treatment $(10 \mathrm{mg} / \mathrm{kg}$ s.c.). The findings are consistent with the observation of Olson et al. (2004) who reported that losartan enhanced NO synthase mRNA levels, protein expression, and $\mathrm{NO}$ production in pulmonary artery endothelium.

The analysis of the media revealed that both smooth muscle cells and extracellular matrix were decreased approximately to a similar extent. The preventive effect of losartan administration on enlargement of arterial wall mass may have been reasonably explained by protective effect of losartan on endothelial cells (Garg and Hassid 1989), and inhibition of proliferative action of Ang II on SMC. Tea et al. (2000) found $\mathrm{AT}_{2}$ receptor-mediated vascular mass regression by stimulating SMC apoptosis in vivo, an effect seen during $\mathrm{AT}_{1}$ receptor blockade. Decreased mass of SMC in the vessel wall may participate in the antihypertensive effect of losartan. Our results revealed that losartan administration also affects extracellular matrix production. Thus, a close relationship between matrix production and mass of SMC seems to be present. Present findings (decreased volume density and CSA of SMC and extracellular matrix) are in good agreement with earlier observations (Lopez et al. 2001, Rosendorf 1996, Varo et al. 2000). They observed that Ang II enhances collagen deposition and matrix components and alters structure and thickness of the arterial wall both resistant and conduit arteries.

In conclusion, the present study has shown the early development of blood pressure and morphological differences between coronary artery of SHR and normotensive Wistar rats aged 9 weeks (myocardial and vessel wall hypertrophy, decrease of volume density and CSA of endothelial cells). Long-term losartan administration resulted in a reduction of BP and myocardial mass in both SHR and Wistar rats. In contrast to Wistar rats losartan prevented the increase of arterial wall mass and beneficially affected mainly volume density and related CSA of endothelial cells in SHR.

\section{Conflict of Interest}

There is no conflict of interest. 


\section{Acknowledgements}

The study was supported by VEGA grant 2/0019/09, Slovak Republic. The authors would like to thank
Dr. Tomáš Hauser (Zentiva) for generous donation of losartan and Mrs. I. Hanáčková for help with housing the animals.

\section{References}

AN SJ, BOYD R, WANG Y, QIU X, WANG HD: Endothelin-1 expression in vascular adventitial fibroblasts. Am $J$ Physiol 290: H700-H708, 2006.

CEBOVÁ M, KRISTEK F, KUNEŠ J: Differential remodeling of carotid artery in spontaneously hypertensive rats and hereditary hypertriglyceridemic rats. Physiol Res 55 (Suppl 1): S81-S87, 2006.

CUNHA RS, DABIRÉ H, BEZIE I, WEISS AM, CHANOUCHE-TERZARA K, LAURENT S, SAFAR ME, LACOLLEY P: Mechanical stress of the carotid artery at the early phase of spontaneous hypertension in rats. Hypertension 29: 992-998, 1997.

DANTAS AP, FRANCO MC, SILVA-ANTONIALLI MM, TOSTES RC, FORTES ZB, NIGRO D, CARVALHO MH: Gender differences in superoxide generation in microvessels of hypertensive rats: role of NAD(P)Hoxidase. Cardiovasc Res 61: 22-29, 2004.

FREEMAN EJ, FERRARIO CM, TALLLANT EA: Angiotensin differentially activate phospholipase D in vascular smooth muscle cells from spontaneously hypertensive and Wistar-Kyoto rats. Am J Hypertension 8: 1105$1111,1995$.

GARG UC, HASSID A: Nitric oxide-generating vasodilators and 8-bromo-cyclic guanosine monophosphate inhibit mitogenesis and proliferation of cultured rat vascular smooth muscle cells. J Clin Invest 83: 1774-1777, 1989.

GEROVÁ M, KRISTEK F, ČAČÁNYIOVÁ S, CEBOVÁ M: Controversial response to acetylcholine and bradykinine in consecutive portions of arterial tree in SHR and SHR treated with NO donors. Braz J Biol Res 38: 959-966, 2005.

GOHLKE P, PEES C, UNGER T: $\mathrm{AT}_{2}$ receptor stimulation increases aortic cyclic GMP in SHRSP by a kinindependent mechanism. Hypertension 31: 349-355, 1998.

KANEKO K, SUSIC D, NUNEZ E, FROHLICH ED: Losartan reduces cardiac mass and improves coronary flow reserve in the spontaneously hypertensive rat. J Hypertens 14: 645-653, 1996.

KRISTEK F: Long-term administration of L-arginine did not influence blood pressure, heart rate, cardiac hypertrophy or arterial wall thickness of spontaneously hypertensive rats. Exp Physiol 83: 595-603, 1998.

KRISTEK F, FÁBEROVÁ V, VARGA I: Long-term effect of molsidomine and pentaerythrityl tetranitrate on cardiovascular system of spontaneously hypertensive rats. Physiol Res 52: 709-717, 2003.

KRISTEK F, KOPRDOVÁ R, CEBOVÁ M: Long-term effects of early administered sildenafil and NO donor on the cardiovascular system of SHR. J Physiol Pharmacol 58: 33-43, 2007.

LEE RMKW, FORREST JB, GARFIELD RE, DANIEL EE: Ultrastructural changes in mesenteric arteries from spontaneously hypertensive rats. A morphometric study. Blood Vessels 20: 72-91, 1983.

LI P, FERRARIO CM, BROSNIHAM KB: Nonpeptide angiotensin II antagonist losartan inhibits thromboxane $\mathrm{A}_{2}$ induced contractions in canine coronary arteries. J Pharmacol Exp Ther 281: 1065-1070, 1997.

LIU H, LEDINGHAM JM, MULLANEY I, LASERTY R: Endothelial function in mesenteric resistance arteries from genetically hypertensive rat. Clin Exp Pharmacol Physiol 29: 405-411, 2002.

LOPEZ B, GONZALES A, VARO N, LAVIADES C, QUEREJETA R, DIEZ J: Biochemical assessment of myocardial fibrosis in hypertensive heart disease. Hypertension 38: 1222-1226, 2001.

MORTON JJ, BEATTIE EC, MACPHERSON F: Angiotensin II receptor antagonist losartan has persistent effects on blood pressure in the young spontaneously hypertensive rat: lack of relation to vascular structure. $J$ Vasc Res 29: 264-269, 1992.

MULVANY MJ, AALKAJAER C, CHRISTENSEN J: Changes in noradrenaline sensitivity and morphology of arterial resistance vessels during development of high blood pressure in spontaneously hypertensive rats. Hypertension 2: 664-671, 1980.

OKAMOTO K, AOKI K: Development of a strain of spontaneously hypertensive rats. Jpn Circ J 27: 282-293, 1963. 
OLIVETTI G, ANVERSA P, MELISSARI M, LOUD AV: Morphometric study of early postnatal development of the thoracic aorta in the rat. Circ Res 47: 417-424, 1980.

OLIVETTI G, MELISSARI M, MARCHETTI G, ANVERSA P: Quantitative structural changes of the rat thoracic aorta in early spontaneous hypertension. Tissue composition, and hypertrophy and hyperplasia of smooth muscle cells. Circ Res 51: 19-26, 1982.

OLSON S, OECKLER R, LI XM, DU LT, TRAGANOS F, ZHAO XM, BURKE-WOLIN T: Angiotensin II stimulates nitric oxide production in pulmonary artery endothelium via the type 2 receptor. Am J Physiol 287: L559L568, 2004.

OWENS GK, SCHWARTZ SM: Alterations in vascular smooth muscle mass in the spontaneously hypertensive rat: role of cellular hypertrophy, hyperploidy and hyperplasia. Circ Res 51: 280-289, 1982.

PAULIS L, LÍŠKOVÁ S, PINTÉROVÁ M, DOBEŠOVÁ Z, KUNEŠ J, ZICHA J: Nifedipine-sensitive noradrenergic vasoconstriction is enhanced in spontaneously hypertensive rats: the influence of chronic captopril treatment. Acta Physiol 191: 255-266, 2007.

POURAGEAUD F, FRESLON JL: Impaired endothelial relaxations induced by agonists and flow in spontaneously hypertensive rat compared to Wistar-Kyoto rat perfused coronary arteries. $J$ Vasc Res 32: 190-199, 1995.

RIZZONI D, PORTERI E, PICCOLI A, CASTELLANO M, BETTONI G, MUIESAN ML, PASINI G, GUELFI D, MULVANY MJ, AGABITI-ROSEI E: Effects of losartan and enalapril on small artery structure in hypertensive rats. Hypertension 32: 305-310, 1998.

ROSENDORF C: The renin-angiotensin system and vascular hypertrophy. J Am Coll Cardiol 28: 803-812. 1996.

RUIZ-GAYO M, SOMOZA B, BRAVO R, FERNANDEZ-ALONSO MS, GONZALES C: Chronic losartan treatment decreases angiotensin II-mediated facilitation of noradrenaline release in caudal artery of spontaneously hypertensive rats. Life Sci 67: 3153-3162, 2000.

SILVA-ANTONIALLI MM, FORTES ZB, CARVALHO MHC, SCIVOLETTO R, NIGRO D: Sexual dimorphism in the response of thoracic aorta from SHRs to losartan. Gen Pharmacol 34: 329-335, 2000.

SOLTIS EE: Alterations in vascular structure and function after short-term losartan treatment in spontaneously hypertensive rats. $J$ Pharmacol Exp Ther 266: 642-646, 1993.

SOLTIS EE, JEWELL AL, DWOSKIN LP, CASSIS LA: Acute and chronic effects of losartan (DUP-753) on bloodpressure and vascular reactivity in normotensive rats. Clin Exp Hypertens 15: 171-184, 1993.

SUO M, KALLIOVALKAMA J, PORSTI I, JOLMA P, TOLVANEN JP, VUOLTEENAHO O, RUSKOAHO H: N ${ }_{-}^{\text {- }}$ nitro-L-arginine methyl ester-induced hypertension and natriuretic peptide gene expression: Inhibition by angiotensin II type 1 receptor antagonist. J Cardiovasc Pharmacol 40: 478-486, 2002.

TEA BS, DER SARKISIAN S, TOUYZ RH, HAMET P, DE BLOIS D: Proapoptotic and growth-inhibitory role of angiotensin II type 2 receptor in vascular smooth muscle cells of spontaneously hypertensive rats in vivo. Hypertension 35: 1069-1073, 2000.

TŐRŐK J, KOPRDOVÁ R, CEBOVÁ M, KRISTEK F: Functional and structural pattern of arterial responses in hereditary hypertriglyceridemic and spontaneously hypertensive rats in early stage of experimental hypertension. Physiol Res 55 (Suppl 1): S65-S71, 2006.

THUBRIKAR MJ, ROBISCEK F: Pressure-induced arterial-wall stress and atherosclerosis. Ann. Thorac Surg 59: 1594-1603, 1995.

VARO N, IRABURU MJ, VARELA M, LOPEZ B, ETAYO JC, DÍEZ J: Chronic AT1 blockade stimulates extracellular collagen type I degradation and reverses myocardial fibrosis in spontaneously hypertensive rats. Hypertension 35: 1197-1202, 2000.

WEIBEL ER, KISTELER GS, SCHERLE WF: Practical stereological methods for morpfometric cytology. J Cell Biol 30: 23-38, 1966.

YOKOYAMA H, AVERILL DB, BROSNIHAN KB, SMITH RD, SCHIFFRIN EL, FERRARIO CM: Role of blood pressure reduction in prevention of cardiac and vascular hypertrophy. Am J Hypertens 18: 922-929, 2005. 